\title{
Exploring the Relative Importance of Factors That Influence Student-Athletes' School-Choice Decisions: A Case Study of One Canadian University
}

\author{
Chris R. Chard \\ Brock University \\ Luke R. Potwarka \\ University of Waterloo
}

\begin{abstract}
Understanding salient factors influencing student-athletes' decisions to attend particular university institutions is of crucial importance to scholars and athletic administrators. Consequently, our research was concerned with two separate but interrelated substantive and methodological objectives: i) to gain insights into the relative importance of 12 school choice decision-making factors influencing Canadian student-athletes; and ii) to explore the efficacy of a multicriteria decision-making (MCDM) method for analyzing data in the context of the current investigation. Specifically, we employed the Analytic Hierarchy Process (AHP) to better understand the relative importance of school choice decision factors. The results of the AHP analysis on Canadian student-athletes' school choice decisionmaking showed that having the desired academic program was the most important influence. This item was almost twice as important as the reputation of the school, and over twice as important as scholarship value, athletic facilities, chance to win, and reputation of the head coach. Of the 12 factors considered, these six had the greatest influence on student-athletes' decision-making. Implications of our findings for research and recruitment efforts are discussed.
\end{abstract}

Keywords: Canadian interuniversity sport (CIS), U sports, analytic hierarchy process (AHP), decision-making, recruiting, school-choice

The ability to recruit talented student-athletes is one of the most important contributing factors to a successful athletic department. Klenosky, Templin, \& Troutman (2001) note that, "the competition to recruit talented student athletes is often as fierce between universities as the actual contests between the schools'

Chard is with the Dept. of Sport Management, Brock University, St. Catharines, Ontario, Canada. Potwarka is with the Department of Recreation and Leisure Studies, University of Waterloo, Waterloo, Ontario, Canada. Address author correspondence to Chris Chard at cchard@brocku.ca. 
athletic teams" (p. 95). Here, recruiting has been described as the most challenging aspect of coaching at the collegiate level (Judson, James, \& Aurand, 2004). This challenge is manifest in the utilization of scarce resources (e.g., human, financial) and compounded in small to midsize athletic departments. Thus, research designed to provide insights into the question posed by Magnusen, Kim, Perrewe, \& Ferris (2014): "How do athletic departments improve recruitment effectiveness" (p. 1266), is important.

From the student-athletes' perspective, choosing which university to attend, where both academic and athletic pursuits will be central, is a significant life decision (Klenosky et al., 2001). Student-athletes have to consider multiple criteria and decision influences when deciding upon postsecondary education alternatives. Deliberations given to scholastic and athletic considerations make the decision on where to attend university multidimensional and complex for student-athletes.

\section{North American Post-Secondary Options for Student-Athletes}

The National Collegiate Athletic Association (NCAA) is based in the United States and is home to approximately 1,100 institutions, housed in over 30 athletic conferences across the country (Brown, Rascher, Nagel, \& McEvoy, 2011). Here, over 460,000 athletes compete under the NCAA banner in 23 different sports (NCAA. org). A second US-based governing body for university sport is the National Association of Intercollegiate Athletics (NAIA). The NAIA has over 260 member schools and is focused on "small athletics programs" (NAIA.org). In 2014/15, over 60,000 athletes competed in 15 sports (NAIA.org).

In Canada, U Sports (formerly the Canadian Interuniversity Sport [CIS]) is the governing body for university athletics. U Sports is home to four conferences that are geographically delineated across the country: Atlantic Universities Athletic Association (AUAA), Réseau du sport étudiant du Québec (RSEQ), Ontario University Athletics (OUA) and the Canada West Universities Athletic Association (CWUAA). Overall, 56 member schools compete in 12 sports accommodating 11,000 athletes each year (cis-sic.ca). Also in Canada, the Canadian Collegiate Athletic Association (CCAA) is the governing body to 94 member institutions competing for ten national championships in seven sports (ccaa.ca). Like U Sports, the CCAA is divided geographically across the country.

Recognizing the multitude of postsecondary school choice options available to competent student-athletes, and the competitive environment within which coaches must recruit, this research is concerned with two separate but interrelated objectives. The first is a desire to understand the relative importance of school choice decision-making factors influencing student-athletes, specifically from a Canadian perspective. The second is to consider the notion of multicriteria decisionmaking (MCDM) in the context of the current investigation. It is clear, given the numerous options available, that competent student-athletes may face a difficult decision on where to pursue their postsecondary athletic and academic interests. Here, it is unlikely that one factor will be used exclusively to make this decision (e.g., it is improbable that a university's location is the only factor considered in 
the assessment). It is far more plausible that multiple factors, such as the school's reputation, athletic and academic facilities, and degree programs available, will all guide the decision process to varying extents. Thus, it is our goal to empirically apply a specific MCDM method, the Analytic Hierarchy Process (AHP), to the current study to better understand the relative importance of school choice decision factors in a Canadian context. Through a case study of one Canadian university in the OUA, our goal was to enhance understanding and gain insights into the following research questions:

1. What is the relative importance of salient factors that influence student-athletes' school-choice decision-making?

2. What is the utility of a specific multicriteria decision-making (MCDM) tool-the AHP-in the context of the current investigation?

\section{Literature Review}

The following sections detail the theoretical foundations of the current research. First, the literature surrounding school-choice decision-making is reviewed. Next, we theoretically frame the investigation through the lens of priority theory; within this discussion, a detailed analysis of the mechanics of the AHP is offered.

\section{School-Choice Decision-Making}

A number of researchers have focused energies on better understanding influences on student-athletes' school choice decisions and influences in the NCAA (i.e., Cooper, 1996; Finley \& Fountain, 2008; Goss, Jubenville, \& Orejan, 2006; Klenosky et al., 2001; Magnusen, Mondello, Kim, \& Ferris, 2011; Popp, Pierce, \& Hums, 2011; Ryan, Groves, \& Schenider, 2007) or the NAIA (Johnson, Jubenville, \& Goss, 2009). These studies have considered numerous contexts including NCAA Division I football freshmen (Klenosky et al., 2001; Treadway, Adams, Hanes, Perrewé, Magnusen, \& Ferris, 2012), NCAA Division I studentathletes more generally (Cooper, 1996; Popp et al., 2011; Ryan et al., 2007), NCAA Division III and/or NAIA student-athletes (Goss et al., 2006; Johnson et al., 2009; Schaeperkoetter, Bass, \& Gordon, 2015), and female softball players in NCAA Division I (Kankey \& Quarterman, 2007), NCAA Division II (Finley \& Fountain, 2008), and community college (Vermillion \& Stoldt 2010). While unanimity on factors influencing school-choice is not present, a number of criteria emerge as important in these prior investigations. That the university offered desired degree programs carried significant influence in some instances (Goss et al., 2006; Kankey \& Quarterman, 2007); the reputation of the university was similarly important (Popp et al., 2011; Vermillion \& Stoldt, 2010). Specifically, in the Popp et al. (2011) investigation, school reputation was more important for domestic versus international student-athletes. Indeed, for this second group, the value of scholarships was the most influential factor; this primary influence is supported in Doyle \& Gaeth (1990), and was the number two factor in Vermillion and Stoldt's (2010) study. The influence of the coach was often revealed to be a top three factor in school-choice decisions (Kankey \& Quarterman, 2007; Klenosky et al., 2001; Popp et al., 2011; Vermillion \& Stoldt, 2010). Further, research energies have recently been directed at better understanding the political 
skills of the coach within the recruiting process (Magnusen et al., 2011; Treadway et al., 2012)

Of the prior investigations, a few have taken a qualitative approach to enhance understandings of school choice decision-making (Finley \& Fountain, 2008; Magnusen et al., 2011; Magnusen et al., 2014; Schaeperkoetter, et al., 2015). However, the majority of researchers in this area have sought to understand the perceived importance or significance of factors in decision making models using quantitative approaches (i.e., Likert-scales) (e.g., Judson, et al., 2004; Johnson, et al., 2009; Goss et al., 2006; Popp et al., 2011). When using such an approach, in theory, respondents could deem every factor to be "very important" to their decision making. In practice, however, certain factors will exert a greater influence on student athletes' decisions to attend one school over another. Consequently, considering the relative importance of factors is critical, as individuals tend not to possess the cognitive capacity to consider all possible elements when presented with a complex decision (Taylor, 1975). For instance, Simon (1982) pioneered the notion of "bounded rationality", which suggests that when facing cognitive strain that results from "information overload" associated with a particular decision, individuals respond by constructing a simplified representation of the problem. Here, the decision maker will rely on simpler heuristics or schemes in the decision-making process (Simon). These simplified decision heuristics or schemes may only be related to a limited number of influences perceived by the individual.

The importance of understanding school choice decision factors and their relative importance for Canadian student-athletes therefore is pertinent when one considers the structure of most Canadian university athletic departments, and the teams operating within them. In their paper concerning sustainable competitive advantage in intercollegiate athletics, Smart and Wolfe (2000) identified resources as a key driver of success; specifically, two resources were discussed: financial and human. Considering the financial context first, Danylchuk and MacLean (2001) note that the funding of Canadian interuniversity sport is a "critical issue" (p. 372). Similarly, Chard, Hyatt and Foster (2013b) found that the overwhelming majority of Canadian university hockey teams' operations are funded through the direct support of the associated institution. Canadian athletic departments, in sum, are not awash with fiscal riches to direct to recruiting initiatives. The second resource issue addressed by Smart and Wolfe (2000) relates to human assets. In U Sports, Chard et al. (2013b) found "the reliance on coaches to multi-task" (p. 253), is noteworthy. Coaches described their roles and responsibilities in multiple areas including: fundraising, managing, counseling, marketing, alumni relations, and, of course, recruiting (Chard et al., 2013b). All of these tasks were in addition to their primary role of coaching. Apparently, coaches were constrained by a lack of human capital to run their teams.

Given these financial and human resource challenges, understanding the relative influence of the most salient factors impacting school choice decisionmaking would be of value to the coaches charged with recruiting and the athletic directors charged with managing departmental resources. Indeed, the apparent human and fiscal constraints within U SPORTS athletics would lead one to believe that understanding influences on potential recruits' school-choice would be a source of competitive advantage. 


\section{Priority Theory and the AHP}

As noted, we employ the AHP to explore the issue of school choice decisionmaking among Canadian student-athletes. The AHP is underpinned by Saaty's priority theory $(1980 ; 1994)$. This theory suggests that decision making involves the comparison of many criteria and subcriteria to prioritize alternatives of a decision (Saaty, 2008). To be sure, any complex decision involves trade-offs (Porter, 2008; Saaty, 2008). Therefore, people need to create priorities for the decision alternatives (e.g., which school to attend) with respect to particular criteria or subcriteria, in terms of which the various alternatives can be evaluated. To complicate the analysis, criteria may be intangible and have no measurements to serve as a guide to rank the alternatives (Saaty, 2008). Priority theory suggests that, via the application of the AHP, a finite set of decision criteria can be established based on subjective judgments of knowledgeable respondents (e.g., student athletes) (Kwiesielewicz, 1998). Here, the utility of AHP is in its ability to address complex MCDM problems; to provide "the objective mathematics to process the inescapably subjective and personal preferences of an individual or a group" (Saaty \& Vargas, 2012, p.33). Indeed, the AHP is an "excellent tool for ranking very incorporeal things" (Klutho, 2013, p.10).

The use of the AHP has been employed in numerous decision making contexts including selecting convention venues (Chen, 2006), choosing a contractor (Fong \& Choi, 2000), selecting vendors' supply chains (Haq \& Kannan, 2006), choosing a catering company (Kahraman \& Cebeci, 2004), and selecting a bank (Phoung \& Har, 2000). To date, however, the AHP has received limited attention among sport researchers with just two studies in the field (Lee \& Walsh, 2011; Lee \& Ross, 2012) known to use the technique. For sure, AHP research has been overlooked entirely by scholars interested in exploring student-athletes' decision to attend postsecondary institutions. We note this deficiency in the sport management literature as an opportunity to contribute to the field. Through this theoretical and analytical approach, we can identify the most salient decision criteria, relative to other factors in the consideration set, upon which student-athletes weigh decisions to attend particular schools. These insights, in turn, can have implications for the design of more effective student-athlete recruitment strategies and communication efforts. We explore the procedures and utility of conducting AHP investigations in more detail in the following section.

\section{Procedures and Utility of Conducting AHP Studies}

AHP is best used through a comprehensive literature review to define the general structure and factors (criteria and subcriteria) that might influence a decision. These factors are then used, through pairwise comparison (criteria vs. criteria; subcriteria vs. subcriteria), to model the decision-making process and understand the most significant factors relative to other considerations when making a decision (Lootsma, 1980). A basic illustration of three factors highlights the process: assume an individual likes to watch hockey twice as much as football. Further, they acknowledge that they prefer watching football twice as much as soccer. Logically, therefore, this individual should prefer to watch hockey about four times as much as soccer. 
When conducting pairwise comparisons limiting analyses to the most salient factors in the decision model is important (Saaty, 2008). Here, while it may seem 'better' to have every conceivable factor included in the decision assessment, an abundance of factors can actually obfuscate individuals' perceptions (Gawlik, 2008). Indeed, Lee and Ross (2012) recently called for future AHP researchers to "reduce the number of factors, if possible, so that respondents have to make fewer comparisons during the survey" (p.165). Saaty (2003) noted $7 \pm 2$ as the maximum number of factors to consider in any level (i.e., criteria, subcriteria); Saaty and Ozdemir (2003) however, were more specific with their thoughts on maximum comparisons: "to serve both consistency and redundancy, it is best to keep the number of elements seven or less" (p. 244). As the number of factors to compare increases (i.e., preference to watch hockey, soccer, football, basketball, tennis, golf, baseball, boxing, swimming, volleyball, MMA), the capacity of the human mind to interpret differences and maintain consistency is reduced. As such, a balance between paring the number of factors analyzed down to a manageable quantity, while simultaneously keeping the analysis robust through inclusion of the most significant considerations in the decisions set, is needed. To assist in this task of factor reduction, Gawlik (2008) promotes the analytical method. Here, factors are included or omitted from an investigation based on the feedback from expert opinions and evaluations. Ultimately, the total number of comparisons in an AHP depends on the number of factors being evaluated within each hierarchy; the equation $\{n(n-1)\} / 2$ captures this relationship.

When making pairwise comparisons between alternatives, a reciprocal matrix representing the comparisons can easily be constructed, as shown below.

$$
A=\left[\begin{array}{cccc}
1 & a_{12} & \cdots & a_{1 n} \\
1 / a_{12} & 1 & \cdots & a_{2 n} \\
\vdots & \vdots & \ddots & \vdots \\
1 / a_{1 n} & 1 / a_{2 n} & \cdots & 1
\end{array}\right]
$$

By dividing each number in the matrix by the sum of its column, the item's relative weight is normalized (Saaty, 2008). Next, the average from each row can be calculated to produce the normalized principal eigenvector-also called the priority vector-which "indicates relative weights within the hierarchy" (Lee \& Ross, 2012, p.158). This process for establishing priority vectors is done within each hierarchy at each level (i.e., criteria level, subcriteria level etc.). The final level of analysis is described as "the global level" (Saaty \& Kearns, 1985), where weights are achieved by multiplying the weight at the criteria level by the weight at the subcriteria level for each factor (Saaty \& Kearns, 1985). Once this is complete, the results lead us to the notion of dominance; here we can understand how much one factor dominates-is "better" or "more important" than-another (Millet \& Saaty, 2000).

To be sure, AHP is a tool with utility for any decision making context. As noted by Duke and Aull-Hyde (2002), given the mathematical basis of the AHP, even one decision maker's opinion is practical for analysis. Respondent size is thus no impediment to AHP analyses (Lee \& Walsh, 2011). Indeed, small sample sizes are commonplace in AHP studies generally (i.e., Chen, 2006; Chiu, Lee, \& 
Lin, 2010; Kurttila, Pesonen, Kangas, \& Kajanus, 2000) and, more specifically, in the only two known studies employing AHP in the sport field (Lee \& Walsh, 2011; Lee \& Ross, 2012).

\section{Method}

To achieve our research objectives, we present an empirical evaluation of $18 \mathrm{U}$ SPORTS student-athletes from one institution competing in the Ontario University Athletics conference within U Sports.

\section{AHP Factor Generation}

To understand the most relevant factors influencing school choice decision-making for student-athletes in U Sports, a 3-staged process was employed. First, a thorough literature review was conducted. Here, the work of Popp et al. (2011), comparing international and domestic student-athletes from NCAA Division I institutions, proved useful. The researchers identified 39 factors influencing school-choice decisions for student-athletes. These factors were drawn from a number of prior studies on student-athletes' school choice influences (i.e., Doyle \& Gaeth, 1990; Finley \& Fountain, 2008; Goss et al., 2006; Judson et al., 2004; Letawsky, Schneider, Pedersen, \& Palmer, 2003). In addition, the current investigation also included other works (i.e., Chard, MacLean, \& Faught, 2013a; Chelladurai \& Riemer, 1997; Cooper, 1996; Dawes \& Brown, 2004; Johnson et al., 2009; Schaeperkoetter, et al., 2015; Treadway, et al., 2012; Vermillion \& Stoldt, 2010). This analysis produced five additional factors that could influence school-choice (i.e., open spot, school colors, community relations program, friend on the team, and previous participation in a summer camp at the university). Table 1 shows the complete list of school choice factors influencing decision-making, identified through the literature review.

In the second stage of factor generation for the AHP, the researchers sought feedback on the literature review findings from an expert panel for content validity and factor reduction purposes. The panel was drawn from a convenience sample of current and former U SPORTS athletes $(n=10)$. Panel members were carefully selected to ensure insights were gleaned from a representative mix of the larger sample of student-athletes under investigation. Specifically, the panel consisted of male and female athletes from both individual and team sport contexts. Panel members also reflected diverse varsity sport experiences (e.g., first year studentathletes, seniors, and recently graduated alumni). Using Gawlik's analytical method (2008), individuals were sent a survey questionnaire and asked to rank the factors within each category (i.e., Athletic experience, Academics etc.), to identify those seen as most influential in school choice decision making.

To further assist in the reduction of comparisons as recommended by Lee and Ross (2012), the researchers held detailed discussions on the possibility of merging any of the attribute categories. After careful judgment, the "School Attributes" and "Academics" categories were joined into one category called "School-Related Attributes (SRA)". Second, "Athletic Experience" and "University Athletic Program" categories were merged under one title named "Athletic Program-Related Attributes (APRA)". "Outside Influences (OI)" remained as a stand-alone category. The final factors and their category assignments were sent to the expert panel for 


\section{Table 1 School Choice Factors Influencing Student-Athletes}

\begin{tabular}{|c|c|c|}
\hline Athletic experience & University Athletic Program & Outside influences \\
\hline $\begin{array}{l}\text { amount of immediate } \\
\text { playing time } \\
\text { amount of travel } \\
\text { liklihood of pro sports } \\
\text { career conference } \\
\text { level of competition } \\
\text { chance for title } \\
\text { value of scholarship } \\
\text { media coverage } \\
\text { schedule } \\
\text { getting to know team } \\
\text { members } \\
\text { recruiting literature/ } \\
\text { website open spot } \\
\text { school colors }\end{array}$ & $\begin{array}{l}\text { reputation of assistant coaches } \\
\text { personality of assistant coaches } \\
\text { reputation of head coach } \\
\text { personality of head coach } \\
\text { recent success of team } \\
\text { tradition } \\
\text { spectator support } \\
\text { athletic facilities } \\
\text { community relations program }\end{array}$ & $\begin{array}{l}\text { influences of friends from } \\
\text { home } \\
\text { acquaintances live in area } \\
\text { advice from relatives } \\
\text { influence of parents } \\
\text { influence of high school } \\
\text { coaches } \\
\text { location in preferable part } \\
\text { of Canada } \\
\text { location of school relative } \\
\text { to home } \\
\text { friend on the team } \\
\text { participated in summer } \\
\text { camp }\end{array}$ \\
\hline & $\begin{array}{l}\text { School attributes } \\
\text { attractiveness of campus } \\
\text { size of school } \\
\text { social atmosphere } \\
\text { overall reputation } \\
\text { campus visit } \\
\text { campus housing } \\
\text { nonathletic support services } \\
\text { nonathletic financial aid }\end{array}$ & $\begin{array}{l}\text { Academics } \\
\text { degree leading to a good } \\
\text { job } \\
\text { academic reputation of } \\
\text { school } \\
\text { school offered desired } \\
\text { academic program } \\
\text { academic and social sup- } \\
\text { port for athletes }\end{array}$ \\
\hline
\end{tabular}

a concluding review. Panelists were asked to confirm that the identified factors captured prominent influences for U SPORTS student-athletes' school choice decision-making. Feedback led to one additional change for the final model: the subcriterion "recent success of the team" and "chance for a title", were deemed to be close enough in context that it would be practical to merge the two. Therefore, the final model was created and is shown in Figure 1.

\section{AHP Data Collection}

Discussions with an athletic director (AD) at one institution in Ontario were conducted to assist with the project. The institution was chosen based on support from the athletic director and geographic proximity between the principal investigators. The AD provided a gatekeeper role (Patton, 2002) for the researchers to gain access 


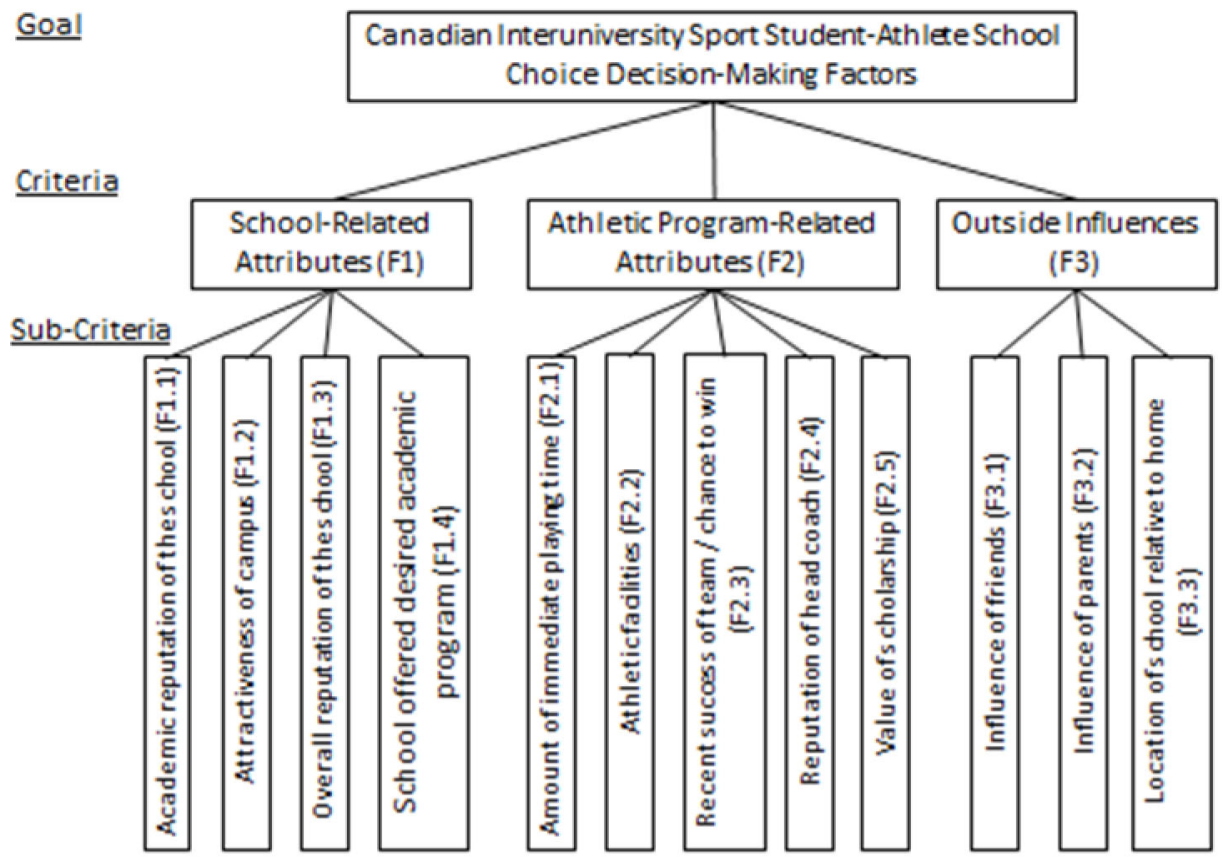

Figure 1 — U SPORTS Student-Athletes' School Choice Influences

to this purposive sample. A purposive sample is acceptable when the group possesses knowledge specific to a particular topic (Liamputtong, 2009). The AD sent an e-mail to every student-athlete enrolled at the institution in 2015, making them aware of the study and asking for their participation. The researchers waited 24 hours from the time of the AD's e-mail before launching the survey to 550 studentathletes. The survey instrument used the AHP software program offered by TransparentChoice. Saaty's (2008) 1-9 point scale was used in the pairwise comparisons of each criterion and subcriterion. Here, a score of 1 represents equal influence of two items; a score of 9 represents the "highest possible order of affirmation of one over another" (Saaty, 2008, p.86).

A total of 95 surveys were returned, however, only 77 of those were completed at a level that made them usable for the study's objective and qualified for further analysis for consistency. AHP requires that judgments be tested for consistency using a consistency ratio (CR). Saaty (2008) notes that a CR of $<0.20$ is acceptable. After applying the CR to the survey responses, 18 surveys were deemed useful for the final analysis. While this number is in line with previous AHP studies (e.g., Chiu et al., 2010; Lee \& Ross, 2012; Lee \& Walsh, 2011), clearly, a sizeable drop-off in serviceable responses occurred when applying the CR to the data. A partial explanation may be found from Lee and Ross (2012), who note that AHP is, "unfamiliar and even complicated to many survey respondents" (p. 164). Importantly, however, "unlike typical consumer surveys where a large number of samples is normally 
suggested, one decision maker's answer is feasible for data analysis when utilizing AHP" (Lee \& Ross, 2012, p164). Here, irrespective of absolute numbers, the specified knowledge the 18 respondents have on this particular case study makes their feedback meaningful, especially given the exploratory nature of the investigation.

\section{AHP Data Analysis and Interpretation}

Results from the pairwise comparisons at the criteria and the subcriteria levels were used to establish the priority vectors at the global level by multiplying the local weight at the subcriteria level by the local weight at the criteria level (Saaty \& Kearns, 1985). For example, if an item with a subcriteria score of 0.224 is housed within a criteria category holding a 0.458 score, multiplying $0.224 \times 0.458$ produces a global weight-or priority-of 0.102 . Given that the sum of all global weights will equal 1, one can interpret this to mean that this item carries (approximately) 10\% influence on the decision at hand. Finally, global weights were divided to produce a relative importance scale highlighting dominance of each factor over one another.

\section{Results}

Table 2 highlights the results from the study broken down by criteria level weight and rank, subcriteria level weight and rank, and finally, global level weight and rank. The results will be discussed in more detail next.

\section{Criteria and Sub-Criteria Level Weights}

At the "criteria" level, the results showed that Athletic Program-Related Attributes $(0.458)$ held the most important factors influencing school-choice, followed closely by School-Related Attributes (0.416). Both of these criteria were approximately 3.5 times more important than Outside Influences $(0.458 / 0.126=3.6$ and 0.416 $/ 0.126=3.3$, respectively).

Within each of the criteria level factors, pairwise comparisons at the subcriteria level produced local results for each item. Specifically, under the APRA category, athletic facilities (0.224), chance to win (0.224), and value of scholarship (0.224) were deemed the most important factors, followed by the reputation of the head coach (0.198), and the amount of immediate playing time (0.131). The SRA results showed that the weighted influences on decision-making were, in order: offering the desired academic program (0.507), reputation of the school overall $(0.264)$, reputation of the school academically (0.143), and the attractiveness of the campus (0.086). Finally, in the Outside Influences category, the influence of parents (0.40), and the location of the school near one's home (0.40) showed the greatest effect on decision-making; the influence of friends carried the least authority within the group (0.20).

\section{Global Weights}

The global weights of each influencing factor were calculated and then correspondingly ranked according to relative influence on school-choice vis-à-vis other factors. To do so, the global weights were divided to produce a relative importance scale 


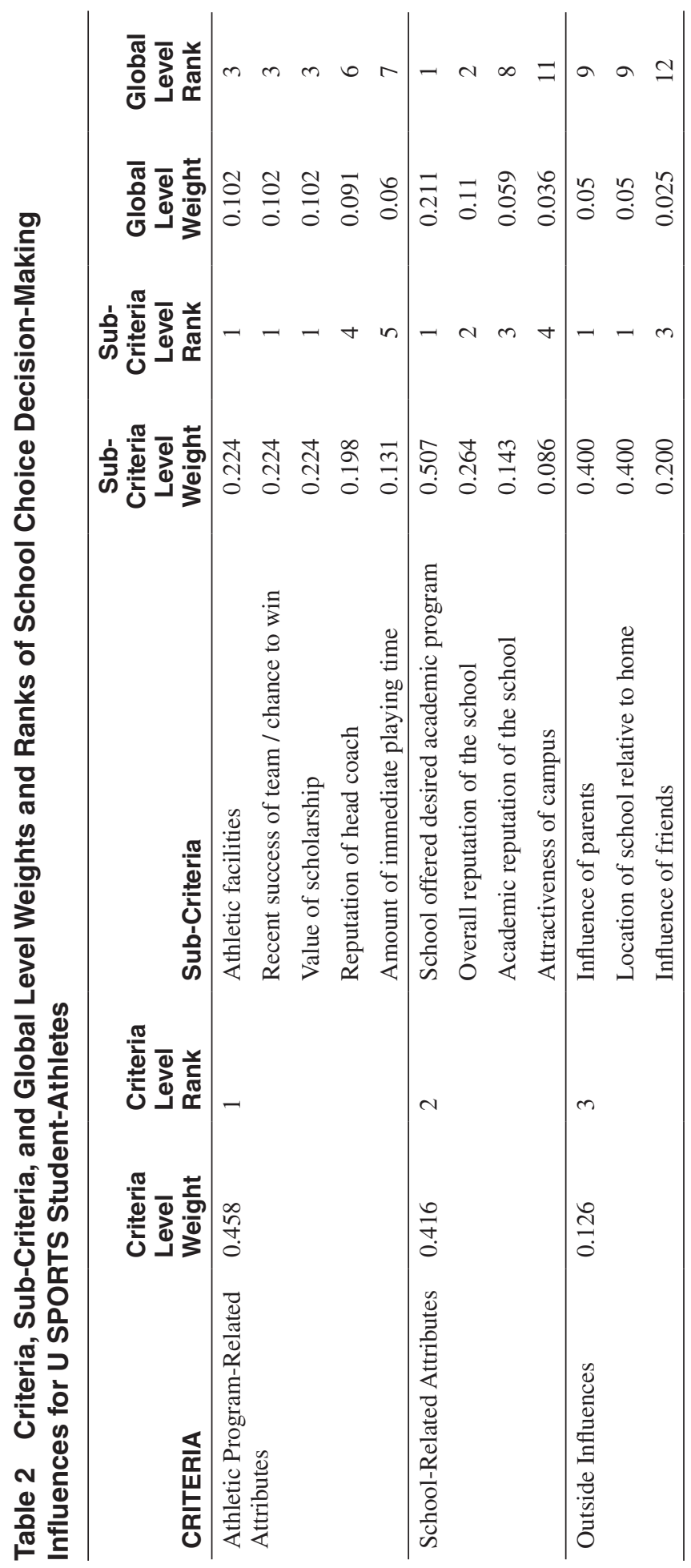


(i.e., desired degree program, $0.211 /$ influence of friends, $0.025=8.44$ ). Thus, the desired degree program carries almost 8.5 times more influence on decision making than friends (See Table 3).

The results showed that the two most prominent factors influencing school choice were School-Related Attributes. The most compelling influence was whether the university offered the student-athletes' desired degree program $(0.211)$; this factor was almost twice as important $(0.211 / 0.110=1.918)$ as the second most influential factor: the overall reputation of the school. Together, these two items influence almost one third $(0.211+0.110=0.321)$ of student-athletes' decision making.

Athletic Program-Related Attributes were also a significant influence on school choice as all five APRA items are listed in the top 7 factors (ranked 3 through 7). Here, athletic facilities, chance to win, and scholarship value (each with a global weight of 0.102) were tied for the third most influential factors for decision-making. Relatively, these three factors were marginally more influential than the reputation of the head coach (1.12 times) but approximately 1.7 times more influential than amount of immediate playing time and academic reputation of the school; they were fully four times (4.08) more influential than friends.

The reputation of the head coach (0.091) and the amount of immediate playing time $(0.060)$ were the 6 th and 7 th ranked influences, respectively. The remaining relative influences on school choice decision-making were the academic reputation of the school (ranked 8th, 0.059), the influence of parents and the location of the school relative to the student-athletes' home (tied for 9th, 0.050), the attractiveness of campus (ranked 11th, 0.036), and the influence of friends (12th, 0.025).

\section{Discussion}

Recognizing the multitude of postsecondary school choice options available to competent student-athletes in Canada, and the competitive environment within which coaches must recruit, it is important to gain insights into the most salient factors that contribute to school-choice decisions. Increasing understandings to better address Magnusen et al.'s (2014) question: "How can athletic departments improve recruitment effectiveness" (p. 1266), may be of particular concern in Canada given the scarcity of resources that exist in many athletic departments (Chard, et al., 2013b; Danylchuk \& MacLean, 2001). Thus, our research was concerned with two separate but interrelated substantive and methodological objectives: (i) to gain insights into the most important postsecondary school choice decision-making factors influencing Canadian student-athletes; and ii) to explore the efficacy of a multicriteria decision-making (MCDM) method for analyzing data in the context of the current investigation. Specifically, we employed the Analytic Hierarchy Process (AHP) in the current study to better understand the relative importance of school choice decision factors. The AHP is underpinned by Saaty's priority theory (1980). This theory suggests that decision making involves many criteria and subcriteria used to rank the alternatives of a decision (Saaty, 2008). It was hoped that successful completion of objectives one and two would lead to managerial insights that could serve as a tool for athletic directors and coaches in U Sports.

Considering the first objective, understanding the decision-making perspectives of a group of student-athletes from one institution in U Sports proved illuminating. First, concerning the twelve factors currently under consideration, it is 


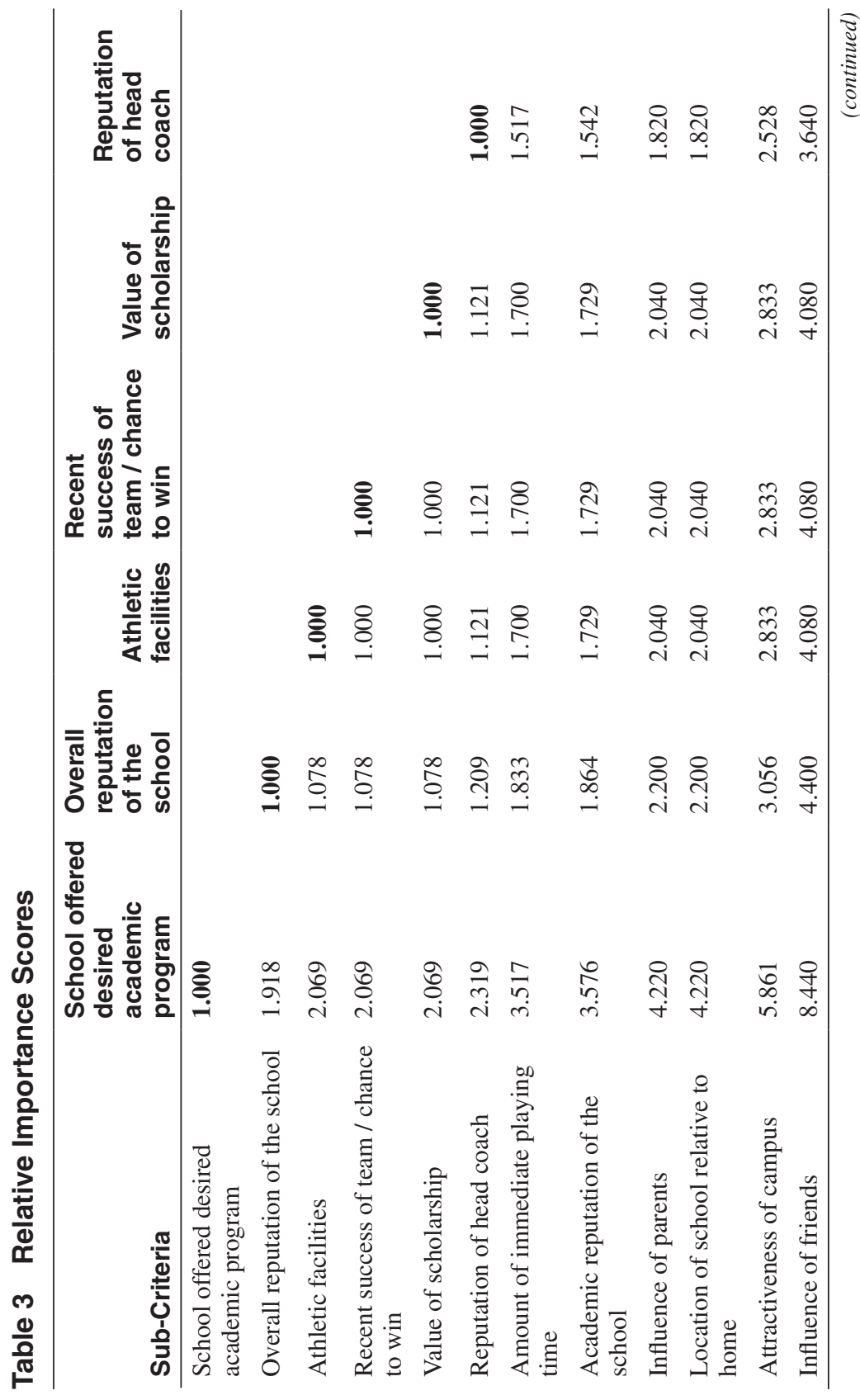




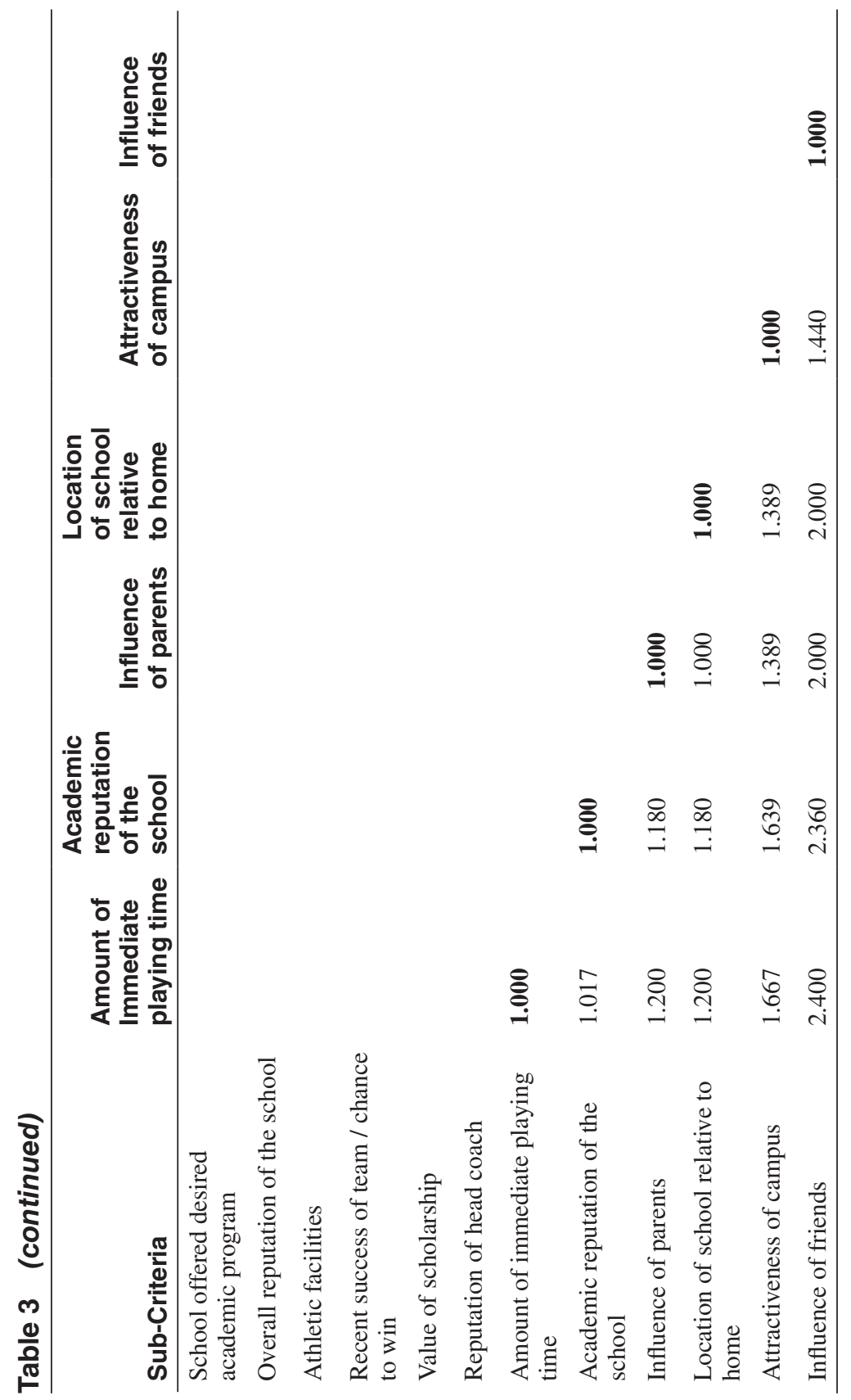


clear that six (desired academic program (0.211), reputation of the school (0.11), scholarship value (0.102), athletic facilities (0.102), chance to win (0.102), and reputation of head coach $(0.091))$ provide the greatest relative influence on school choice decision-making.

Of interest, the two most salient influences on school choice decision-making were, largely, beyond the direct control or management of athletic department personnel. First, the school offering the desired academic program was deemed the most important criteria (0.211) relative to other consideration factors for the Canadian student-athletes. Many studies in the area of student recruitment in the United States note the degree program as being influential in decision-making (i.e., Johnson et al., 2009; Judson et al., 2004; Kankey \& Quarterman, 2007); however, the current findings align with Goss et al. (2006) who acknowledged the "critical importance" (p. 124) of academic programs on school choice decision-making. Here, Goss et al.'s (2006) study of small colleges and universities seems more in line with decision influences in U Sports. Clearly, athletic directors and coaches would be wise to understand degree programs that student-athletes wish to pursue, and work with school administrators to remain up-to-date in these areas.

The overall reputation of the school was the second most noteworthy criteria influencing school choice decisions (0.11). This finding aligns with previous work (i.e., Pauline, 2010; Popp et al., 2011), specifically considering domestic student-athletes, as was the case in the current investigation. Interestingly, the need to manage the university brand has been studied before (Jevons, 2006; Judson, Aurand, Gorchels, \& Gordon, 2008; Chapleo, 2010) with an eye on attracting the wider student population, faculty and staff. Clearly, however, the influence of the university brand on student-athletes in Canada is also notable.

Vermillion and Stoldt's (2010) study on community college softball players may provide some insights on the importance of degree programs and school reputation when influencing school-choice. Vermillion and Stoldt (2010) noted the lack of opportunities to play professional softball, after university graduation, as a reason for academic factors to take precedence in decision-making. Similarly, U Sports is not traditionally viewed as a springboard for professional athletes' development (Chard, 2013). Indeed, decision factors identified in previous studies, such as "level of competition" (Popp et al., 2011), or the "chance for a pro career" (Klenosky et al., 2001) seem minor in the Canadian context.

Numerous studies have identified scholarship value or support as influential in school choice decision-making (Chard et al., 2013a; Doyle \& Gaeth, 1990; Finley \& Fountain, 2008; Popp et al., 2011). It is somewhat unsurprising therefore that scholarship value is a significant influence in the current investigation (0.102). Further, discrepancies exist in terms of maximum allowable financial offerings among the various conferences in U Sports; this could present recruiting challenges to schools in the OUA, where more rigorous scholarship policies exist (Chard et al., 2013b). Further, the threat of "brawn drain" (Bale, 1991; Miller \& Kerr, 2002), where Canadian athletes pursue opportunities in the United States that are deemed more lucrative, is important for U SPORTS athletic directors to consider. While the scholarship system in U Sports has not historically been very robust (Chard et al., 2013b; Hall, Slack, Smith, \& Whitson, 1991), it may be that Canadian student-athletes are influenced by opportunities for financial remuneration in exchange for their athletic talents. Here, the underlying motivation could 
be driven from both a financial and/or ego perspective (Finley \& Fountain, 2008; Magnusen et al., 2014); regardless, the incentive exists and must be considered by athletic administrators in Canada.

Consistent with previous research, U SPORTS student-athletes noted the significant influence of athletic facilities (i.e., Judson et al., 2004; Johnson et al., 2009; Popp et al., 2011) and the chance to win (i.e., Chard et al., 2013a; Popp et al., 2011) in their decision-making; here, both criteria were deemed equivalent (0.102) to scholarship value. Clearly, athletic facilities, where varsity competitors will log significant hours honing athletic skills, are seen as influential to student-athletes' athletic experience. Similarly, the sense that a student-athlete might experience victory in their athletic endeavors-a chance to win-during what amounts to a short varsity career, was seen to be influential.

The last item of note when considering influences on U SPORTS athletes' school choice decision-making relates to the teams' head coach. While the current study's respondents identified coaches as having an undeniable influence (0.091), of interest, they did not place as much importance on this individual as seen in many of the studies conducted with athletes in the NCAA. Indeed, much of the previous research on student recruitment identified the coach as a top three factor influencing student-athletes' school choice (i.e., Goss et al., 2006; Johnson et al., 2009; Kankey and Quarterman, 2007; Vermillion \& Stoldt, 2010). Perhaps, coaches in the NCAA are still seen as a vehicle to help athletes pursue professional sporting aspirations (i.e., Klenosky et al., 2001), while in Canada, U SPORTS sport is not viewed in such progressive terms.

The second objective of the investigation was to consider the utility of the Analytic Hierarchy Process in the context of the current research. The utility of the AHP, and the underpinning application of priority theory, was in its ability to identify salient decision criteria upon which student-athletes weigh alternatives to attend particular schools. Importantly, empirically applying the AHP to the current study helped us understand the relative importance of school choice decision factors. Most previous studies (i.e., Goss et al., 2006; Judson et al., 2004; Kankey \& Quarterman, 2007; Popp et al., 2011; Vermillion \& Stoldt, 2010) use a Likert-scale survey questionnaire to ascertain importance or significance of various factors. For example, "on a scale of 1-7, how influential is scholarship value to your decision to attend a particular institution?" Here, criteria are viewed in isolation; theoretically, every item could be allocated a score of 7 (very important). The AHP, in contrast, forces comparison of each item to produce a relative scale of importance. For example, the influence of quality facilities is twice as important as a school's location and almost three times as important as campus attractiveness. These insights should be valuable from a resource allocation perspective. Indeed, through comparison, priority theory involves analyses of many criteria and subcriteria which can then be used to rank the alternatives of a decision (Saaty, 2008) and focus managerial attention to the most salient areas of influence.

Through completion of objectives one and two, it was felt that managerial insights could be garnered to assist athletic directors and coaches in U Sports to better manage the limited resources available to them (Chard et al., 2013b; Danylchuk \& MacLean, 2001; Smart \& Wolf, 2000) and recruit more effectively (Magnusen et al., 2014). The results of the current study show that this is indeed the case. It is evident that the top six criteria (desired academic program, reputation of 
the school, scholarship value, athletic facilities, chance to win, and reputation of head coach) carry great sway on school choice decision-making. Further, desired academic program and reputation of the school are particularly influential. Clearly, when allocating limited resources, these key areas should garner greater attention. This is not to say however that the bottom six criteria (amount of immediate playing time, academic reputation of the school, influence of parents, location of school relative to home, attractiveness of campus, and influence of friends) are inconsequential. From a managerial perspective, it is simply the case that the relative importance of these criteria diminishes in comparison with the top six.

\section{Implications and Conclusions}

For the purpose of this investigation, we sought to increase understanding in response to Magnusen et al., (2014) who asked: "How do athletic departments improve recruitment effectiveness?" (p. 1266). Specifically, we conducted a case study of one university's athletic department in Ontario, Canada to answer the following research questions:

1. What is the relative importance of salient factors that influence student-athletes' school-choice decision-making?

2. What is the utility of a specific multicriteria decision-making (MCDM) tool-the AHP-in the context of the current investigation?

The efficacy of such an investigation is evident when one is aware of the resource challenges present within most athletic departments in Canada. While nuances will certainly exist between the different institutions within U Sports, the information garnered from the current case study investigation provides practical implications for administrators to use. Foremost, athletic directors and coaches should be acutely aware of the degree programs that student-athletes seek to fulfill their postsecondary scholastic ambitions. Here, working internally with the Registrar's office to better understand highly desirable programs would be worthwhile; gathering information from current student-athletes on program satisfaction would be similarly useful. Indeed, the academic program was fully 3.5-4 times more influential than the amount of immediate playing time, influence of parents, and location of the school.

Likewise, understanding the university's brand or reputation would serve coaches and athletic directors well in recruiting meetings. Given that the school's overall reputation was almost twice as important as its academic reputation, any initiatives to enhance the university brand should be promoted. And, as important, athletic directors and coaches should be knowledgeable on any crisis situations (i.e., history of faculty/employee strikes) that could negatively affect brand perceptions.

From a practical perspective, the influence of scholarships, facilities, and winning were all equally important and influenced almost one third of the overall school choice decision-making. To be sure, directing resources to those key areas is hardly a ground breaking discovery; however, in an environment where financial discrepancies, in terms of scholarship offerings, exists between the various $U$ SPORTS conferences (Chard et al., 2013b), continuing to find creative ways to fund student-athletes in the OUA is paramount. Here, greater resourcing for financial 
support could, potentially, lead to more successful results on the field of play; both, very influential decision factors. Further, an audit of capital infrastructure and facilities, in comparison with other universities in the OUA specifically and U SPORTS more broadly, would provide relevant information for coaches and athletic directors to use in recruiting meetings.

Finally, practical implications derived from the study relate to the influence of parents and the proximity of one's university campus to a potential recruit's home. The results infer that geography and parental input, relatively speaking, are no impediment to school choice. Indeed, eight other factors were deemed more influential, in some cases, significantly more. Here, directing resources to scouting throughout the country, whether that is coaches traveling and/or utilizing the expertise of local scouts, may prove fruitful.

To be clear, it is not the intention of the authors to generalize the current findings to all athletic departments in Canada and/or the United States. Rather, the hope is the current findings provide a framework for dialogue and assessment of current practices within athletic departments across the continent generally, but within $\mathrm{U}$ Sports and the institution under investigation more specifically.

Given the competitive nature of recruitment (Klenosky et al., 2001) and the myriad options available to competent Canadian student-athletes, understanding influences on these individuals' school choice decision-making is valuable. Here, literature on the general topic of athlete recruitment is available; however, the focus is almost exclusively centered on schools in the NCAA. Specific attention to the $150+$ institutions in Canada, operating under the umbrellas of U Sports and CCAA is almost nonexistent. This study was conducted to address this specific gap in the literature.

In conclusion, by understanding the most salient factors influencing studentathletes' school choice decision-making, athletic directors and coaches can best position their offering to meet the desires of individuals weighing competing options in the marketplace. Here, understanding how "athletic departments improve recruitment effectiveness" (Magnusen et al., 2014, p. 1266) becomes enhanced. Through delivery against expectations, it is hoped that the student-athletes' university experience might also be enhanced. In the current study, a school offering desired academic programs with a solid reputation were highly influential factors. Further, opportunities for scholarship resources, on a winning team that played in quality facilities with a highly reputable coach were also of influence.

\section{Limitations and Future Directions}

Our study is not without limitations. First, when using the AHP, a necessary starting point is to generate relevant factors to guide the investigation. Given that there is "no one correct or uniform way to generate factors" (Lee \& Walsh, 2011, p.368), we conducted a thorough literature review and then employed an expert panel to assist in this process (Gawlik, 2008). It is possible, however, that the selected factors did not capture every attribute germane to school choice decision-making in Canada. Secondly, the study was focused on one institution in Ontario, Canada. Here, it is possible that unique features at other institutions may produce varying results. Thus, the intention here is not to generalize findings. Third, the AHP is a cognitive task requiring respondents to carefully process pairwise comparisons 
to arrive at a judgment or preference. The nature of such a collection technique necessitates consistencies among responses; here, a number of respondents' answers contravened stipulated consistency ratios thereby reducing the number of usable surveys. However, unlike traditional survey tools, the AHP does not require large samples to provide utility. Here, "a relatively small sample size is natural" (Lee \& Ross, 2012, p. 164) and even one individual with knowledge is feasible to analyze (Duke \& Aull-Hyde, 2002).

Future studies should consider other universities and athletic departments that compete within U Sports. Understanding if regional differences influence studentathletes' school choice would be of interest. Further, utilizing the AHP in other contexts (i.e., NCAA, NAIA, CCAA) would be worthwhile.

\section{References}

Bale, J. (1991). The brawn drain: Foreign student-athletes in American universities. Champaign-Urbana, IL: University of Illinois Press.

Brown, M.T., Rascher, D.A., Nagel, M.S., \& McEvoy, C.D. (2011). Financial Management in the Sport Industry. Scottsdale, Arizona: Holcomb Hathaway.

CCAA.ca. (2015). CCAA Overview. Retrieved February 15, 2015 from http://www.ccaa. ca/overview-s14861

Chapleo, C. (2010). What defines "successful" university brands? International Journal of Public Sector Management, 23(2), 169-183. doi:10.1108/09513551011022519

Chard, C. (2013). Understanding the brand meaning of the Canadian Interuniversity Sport hockey league: An insurance policy if all else fails! Sport in Society, 16(3), 327-339. doi:10.1080/17430437.2013.779853

Chard, C., MacLean, J., \& Faught, B. (2013a). Managing athletic department touch points: A case study of one institution using importance-performance analysis. Journal of Intercollegiate Sport, 6(2), 196-212. doi:10.1123/jis.6.2.196

Chard, C.R., Hyatt, C., \& Foster, W.M. (2013b). Assets and obstacles: An analysis of OUA hockey from the coaches' perspective. Sport, Business and Management. International Journal (Toronto, Ont.), 3(3), 246-259.

Chelladurai, P., \& Riemer, H.A. (1997). A classification of facets of athlete satisfaction. Journal of Sport Management, 11(2), 133-159. doi:10.1123/jsm.11.2.133

Chiu, W.Y., Lee, Y.D., \& Lin, T.Y. (2010). Performance evaluation criteria for personal trainers: An analytical hierarchy process approach. Social Behavior and Personality, 38(7), 895-905. doi:10.2224/sbp.2010.38.7.895

Chen, C.F. (2006). Applying the analytical hierarchy process (AHP) approach to convention site selection. Journal of Travel Research, 45(2), 167-174. doi:10.1177/0047287506291593

CIS (2015). History of the CIS. Retrieved February 15, 2015 from cis-sic.ca/information/ members_info/pdfs/pdf_elig_pack/14-15/athletes_guide.pdf

Cooper, K. (1996). What the basketball prospect wants to know about you! Coach and Athletics Director, 65(7), 24-26.

Danylchuk, K.E., \& MacLean, J. (2001). Intercollegiate athletics in Canadian universities: Perspectives on the future. Journal of Sport Management, 15(4), 364-379. doi:10.1123/ jsm.15.4.364

Dawes, P.L., \& Brown, J. (2004). The composition of consideration and choice sets in undergraduate university choice: An exploratory study. Journal of Marketing for Higher Education, 14(2), 37-59. doi:10.1300/J050v14n02_03

Doyle, C.A., \& Gaeth, G.J. (1990). Assessing the Institutional Choice Process of StudentAthletes. Research Quarterly for Exercise and Sport, 61(1), 85-92. PubMed doi:10.1 080/02701367.1990.10607482 
Duke, J.M., \& Aull-Hyde, R. (2002). Identifying public preferences for land preservation using the analytic hierarchy process. Ecological Economics, 42(1), 131-145. doi:10.1016/S0921-8009(02)00053-8

Finley, P., \& Fountain, J.J. (2008). An application of means-end theory to analyze the college selection process of female athletes at an NCAA division II-university. The Sport Journal, 11(2). Retrieved August 6, 2015, from https://www.questia.com/ $\mathrm{read} / 1 \mathrm{G} 1-210441826 / \mathrm{an}$-application-of-means-end-theory-to-analyze-the

Fong, P.S.W., \& Choi, S.K.Y. (2000). Final contractor selection using the analytical hierarchy process. Construction Management \& Economics, 18(5), 547-557.

Gawlik, R. (2008). Preliminary criteria reduction for the application of Analytic Hierarchy Process method. Munich Personal RePEc Archive MPRA, 45348.

Goss, B.D., Jubenville, C.B., \& Orejan, J. (2006). An examination of influences and factors on the institutional selection processes of freshman student-athletes at small colleges and universities. Journal of Marketing for Higher Education, 16(2), 105-134. doi:10.1300/J050v16n02_05

Hall, A., Slack, T., Smith, G., \& Whitson, D. (1991). Sport in Canadian society. Toronto, Ontario: McClelland \& Stewart.

Haq, A.N., \& Kannan, G. (2006). Fuzzy analytical hierarchy process for evaluating and selecting a vendor in a supply chain model. The International Journal of Advanced Manufacturing Technology, 29(7-8), 826-835

Johnson, G.R., Jubenville, C., \& Goss, B. (2009). Using institutional selection factors to develop recruiting profiles: Marketing small, private colleges and universities to prospective student-athletes. Journal of Marketing for Higher Education, 19(1), 1-25. doi:10.1080/08841240902904513

Jevons, C. (2006). Universities: a prime example of branding going wrong. Journal of Product and Brand Management, 15(7), 466-467. doi:10.1108/10610420610712856

Judson, K.M., Aurand, T.W., Gorchels, L., \& Gordon, G.L. (2008). Building a university brand from within: University administrators' perspectives of internal branding. Services Marketing Quarterly, 30(1), 54-68. doi:10.1080/15332960802467722

Judson, K.M., James, J.D., \& Aurand, T.W. (2004). Marketing the university to studentathletes: understanding university selection criteria. Journal of Marketing for Higher Education, 14(1), 23-40. doi:10.1300/J050v14n01_02

Kahraman, C., Cebeci, U., \& Ruan, D. (2004). Multi-attribute comparison of catering service companies using fuzzy AHP: The case of Turkey. International Journal of Production Economics, 87(2), 171-184.

Kankey, K., \& Quarterman, J. (2007). Factors influencing the university choice of NCAA division I softball players. The SMART Journal, 3(2), 35-49.

Klenosky, D.B., Templin, T.J., \& Troutman, J.A. (2001). Recruiting student athletes: A means-end investigation of school-choice decision making. Journal of Sport Management, 15(2), 95-106. doi:10.1123/jsm.15.2.95

Klutho, S. (2013). Mathematical Decision Making. An Overview of the Analytic Hierarchy Process. Retrieved June 23, 2015 from http://www.whitman.edu/mathematics/ SeniorProjectArchive/2013/Klutho.pdf.

Kurttila, M., Pesonen, M., Kangas, J., \& Kajanus, M. (2000). Utilizing the analytic hierarchy process (AHP) in SWOT analysis - a hybrid method and its application to a forest-certification case. Forest Policy and Economics, 1(1), 41-52. doi:10.1016/ S1389-9341(99)00004-0

Kwiesielewicz, M. (1998). A note on the fuzzy extension of Saaty's priority theory. Fuzzy Sets and Systems, 95(2), 161-172. doi:10.1016/S0165-0114(96)00329-6

Lee, S., \& Ross, S.D. (2012). Sport sponsorship decision making in a global market: An approach of Analytic Hierarchy Process (AHP). Sport, Business and Management. International Journal (Toronto, Ont.), 2(2), 156-168. 
Lee, S., \& Walsh, P. (2011). SWOT and AHP hybrid model for sport marketing outsourcing using a case of intercollegiate sport. Sport Management Review, 14(4), 361-369. doi:10.1016/j.smr.2010.12.003

Letawsky, N.R., Schneider, R.G., Pedersen, P.M., \& Palmer, C.J. (2003). Factors influencing the college selection process of student-athletes: Are their factors similar to non-athletes? College Student Journal, 37(4), 604-610.

Liamputtong, P. (2009). Qualitative research methods (3 ${ }^{\text {rd }}$ ed.). New York: Oxford.

Lootsma, F.A. (1980). Saaty's priority theory and the nomination of a senior professor in operations research. European Journal of Operational Research, 4(6), 380-388. doi:10.1016/0377-2217(80)90189-7

Magnusen, M.J., Kim, Y., Perrewé, P.L., \& Ferris, G.R. (2014). A critical review and synthesis of student-athlete college choice factors: Recruiting effectiveness in NCAA sports. International Journal of Sports Science \& Coaching, 9(6), 1265-1286. doi:10.1260/1747-9541.9.6.1265

Magnusen, M.J., Mondello, M., Kim, Y.K., \& Ferris, G.R. (2011). Roles of recruiter political skill, influence strategy, and organization reputation in recruitment effectiveness in college sports. Thunderbird International Business Review, 53(6), 687-700. doi:10.1002/ tie. 20445

Miller, P., \& Kerr, G. (2002). The athletic, academic, and social experiences of intercollegiate student athletes. Journal of Sport Behavior, 25(4), 346-367.

Millet, I., \& Saaty, T. L. (2000). On the relativity of relative measures-accommodating both rank preservation and rank reversals in the AHP. European Journal of Operational Research, 121(1), 205-212.

NAIA.org. (2015). About the NAIA. Retrieved February 15, 2015 from http://www.naia. org/ViewArticle.dbml?ATCLID=205323019

Patton, M.Q. (2002). Qualitative research and evaluation methods (3rd ed.). Thousand Oaks, CA: Sage Publications, Inc.

Pauline, J. (2010). Factors influencing college selection by NCAA Division I, II, and III lacrosse players. The ICHPER-SD Journal of Research in Health, Physical Education, Recreation, Sport \& Dance, 5(2), 62.

Phuong Ta, H., \& Yin Har, K. (2000). A study of bank selection decisions in Singapore using the analytical hierarchy process. International Journal of Bank Marketing, 18(4), 170-180.

Popp, N., Pierce, D., \& Hums, M.A. (2011). A comparison of the college selection process for international and domestic student-athletes at NCAA Division I universities. Sport Management Review, 14(2), 176-187. doi:10.1016/j.smr.2010.08.003

Porter, M.E. (2008). On competition. Boston, MA: Harvard Business Review Press.

Ryan, C.J., Groves, D., \& Schenider, R. (2007). A study of factors that influence high school athletes to choose a College or University, and a model for the development of player decisions. College Student Journal, 41(3), 532-539.

Saaty, T.L. (2003). Decision-making with the AHP: Why is the principal eigenvector necessary. European Journal of Operational Research, 145(1), 85-91. doi:10.1016/ S0377-2217(02)00227-8

Saaty, T.L. (2008). Decision making with the analytic hierarchy process. International Journal of Services Sciences, 1(1), 83-98. doi:10.1504/IJSSCI.2008.017590

Saaty, T.L., \& Kearns, K.P. (1985). Analytic planning: The organization of systems. Elmsford, NY: Pergamon Press Inc.

Saaty, T.L. (1980). The Analytic Hierarchy Process. New York: McGraw Hill.

Saaty, T.L. (1994). How to make a decision: The Analytic Hierarchy Process. Interfaces, 24(6), 19-43. doi:10.1287/inte.24.6.19

Saaty, T.L., \& Ozdemir, M.S. (2003). Why the magic number seven plus or minus two. Mathematical and Computer Modelling, 38(3), 233-244. doi:10.1016/S0895-7177(03)90083-5 
Saaty, T.L., \& Vargas, L.G. (2012). The seven pillars of the analytic hierarchy process. In Models, Methods, Concepts \& Applications of the Analytic Hierarchy Process (pp. 23-40). NY: Springer. doi:10.1007/978-1-4614-3597-6_2

Schaeperkoetter, C.C., Bass, J.R., \& Gordon, B.S. (2015). Student-Athlete School Selection: A Family Systems Theory Approach. Journal of Intercollegiate Sport, 8(2), 266-286. doi:10.1123/jis.2015-0003

Simon, H.A. (1982). (Vol. 3. Models of bounded rationality: Empirically grounded economic reason. Cambridge, MA: MIT Press.

Smart, D.L., \& Wolf, R.A. (2000). Examining Sustainable Competitive Advantage in Intercollegiate Athletics: A Resource-Based View. Journal of Sport Management, 14(2), 133-153. doi:10.1123/jsm.14.2.133

Taylor, R.N. (1975). Psychological determinants of bounded rationality: Implications for decision-making strategies. Decision Sciences, 6(3), 409-429. doi:10.1111/j.1540-5915.1975.tb01031.x

Treadway, D.C., Adams, G., Hanes, T.J., Perrewé, P.L., Magnusen, M.J., \& Ferris, G.R. (2012). The roles of recruiter political skill and performance resource leveraging in NCAA football recruitment effectiveness. Journal of Management, 40(6), 1607-1626. doi: $10.1177 / 0149206312441836$

Vermillion, M., \& Stoldt, G.C. (2010). College choice factors influencing community college softball players. Journal of Coaching Education, 3(1), 1-20. doi:10.1123/jce.3.1.1 